\title{
Biological characteristics of side population cells in a self-established human ovarian cancer cell line
}

\author{
ZHENTONG WEI $^{1,2}$, SHUANG LV ${ }^{1}$, YISHU WANG ${ }^{1}$, MEIYU SUN $^{1}$, GUANGFAN CHI $^{1}$, \\ JUN GUO $^{1}$, PEIYE SONG ${ }^{1}$, XIAOYU FU ${ }^{1}$, SONGLING ZHANG ${ }^{2}$ and YULIN LI ${ }^{1}$ \\ ${ }^{1}$ Key Laboratory of Pathobiology, Ministry of Education, Norman Bethune College of Medicine, Jilin University; \\ ${ }^{2}$ Department of Gynecologic Oncology, The First Hospital of Jilin University, Changchun, Jilin 130021, P.R. China
}

Received February 12, 2015; Accepted April 8, 2016

DOI: $10.3892 / 01.2016 .4565$

\begin{abstract}
The aim of the present study was to establish an ovarian cancer (OC) cell line from ascites of an ovarian serous cystadenocarcinoma patient and investigate the biological characteristics of its side population (SP) cells. The OC cell line was established by isolating, purifying and subculturing primary cells from ascites of an ovarian serous cystadenocarcinoma patient (stage IIIc; grade 3). SP and non-SP (NSP) cells were isolated by fluorescence-activated cell sorting and cultured in serum-free medium and soft agar to compare the tumorsphere and colony formation capacities. Furthermore, SP and NSP cell tumorigenesis was examined by subcutaneous and intraperitoneal injection of the cells to non-obese diabetic/severe combined immune deficiency (NOD/SCID) mice. Drug resistance to cisplatin was examined by cell counting kit- 8 . The OC cell line was successfully established from ascites of an ovarian serous cystadenocarcinoma patient, which exhibited properties similar to primary tumors subsequent to $>50$ passages and $>2$ years of culture. The SP cell ratio was $0.38 \%$ in the OC cell line, and a similar SP cell ratio $(0.39 \%)$ was observed when sorted SP cells were cultured for 3 weeks. Compared with NSP cells, SP cells exhibited increased abilities in differentiation and tumorsphere and colony formation, in addition to the formation of xenografted tumors and ascites and metastasis of the tumors in NOD/SCID mice, even at low cell numbers $\left(3.0 \times 10^{3}\right.$ cells $)$. The xenografted tumors demonstrated histological features similar to primary tumors and expressed the ovarian serous cystadenocarcinoma marker
\end{abstract}

Correspondence to: Dr Yulin Li, Key Laboratory of Pathobiology, Ministry of Education, Norman Bethune College of Medicine, Jilin University, 126 Xinmin Street, Changchun, Jilin 130021, P.R. China E-mail: ylli@jlu.edu.cn

Professor Songling Zhang, Department of Gynecologic Oncology, The First Hospital of Jilin University, 71 Xinmin Street, Changchun, Jilin 130021, P.R. China

E-mail: slzhang@jlu.edu.cn; zsongling12345@126.com

Key words: ovarian cancer, side population cells, tumorigenesis, drug resistance
CA125. In addition, SP cells demonstrated a significantly stronger drug resistance to cisplatin compared with NSP and unsorted cells, while treatment with verapamil, an inhibitor of ATP-binding cassette transporters, potently abrogated SP cell drug resistance. In conclusion, the present study verified SP cells from an established OC cell line and characterized the cells with self-renewal, differentiation, proliferation, tumorigenesis and stronger drug resistance capacities.

\section{Introduction}

Ovarian cancer (OC) is the leading cause of mortality resulting from gynecological cancers, and worldwide, $\sim 114,000$ patients succumb to OC annually (1). Although OC patients exhibit a 5-year survival rate of $90 \%$ when treated at an early stage, $80 \%$ of patients cannot be diagnosed until the advanced stages; therefore, the 5-year survival rate is $30 \%$ (2). OC recurrence occurs in $70 \%$ of patients following surgery and platinum-based chemotherapy combined treatments, which causes patients to become insensitive to chemotherapy (3). Consequently, tumor recurrence and drug resistance are two common set-backs in the treatment of OC $(4,5)$. Cancer stem cells (CSCs) are a type of tumor cell that possess an unlimited potential for self-renewal and may differentiate into multiple tumor cell types (6). Numerous studies have demonstrated that CSCs possess various characteristics, including a silent phenotype, enhanced DNA repair capacity, expression of ATP-binding cassette (ABC) transporters and anti-apoptotic proteins, and resistance to conventional chemotherapy and radiotherapy (6-14). Conventional chemotherapy may eliminate the majority of tumor cells, but it has little impact on rare stem cell-like cells; and remaining CSCs cause tumor recurrence and metastasis. Therefore, studies concerning cancer should consider CSCs as a vital target to achieve the complete ablation of tumors, and should not solely focus on temporarily shrinking the tumor mass.

Goodell et al (15) reported that a small cell population isolated from murine bone marrow demonstrated distinct fluorescence-activated cell sorting (FACS) results compared with the main cell population, termed the side population (SP) cells. Numerous studies have demonstrated that SP cells, isolated from numerous tumors, richly contain tumor-initiating cells that possess stem cell characteristics (16-20). A 
low-fluorescence staining phenotype is mediated by $\mathrm{ABC}$ transporters (21), which provide a functional method for isolating SP cells.

Although SP cells have been successfully isolated from certain human and mouse ovarian cell lines $(22,23)$, the present study established an immortalized OC cell line from primary cells in ascites and identified SP cells from this cell line. Additionally, the present study investigated the biological characteristics of the SP cells, including differentiation and tumorsphere and colony formation, in addition to xenografted tumor formation and ascites, metastasis and drug resistance of the xenograft tumors.

\section{Materials and methods}

Establishment of an ovarian cancercell line. Primary cells were isolated from ascites of an ovarian serous cystadenocarcinoma patient. Briefly, primary cells were harvested by centrifugation at $300 \mathrm{x} \mathrm{g}$ for $5 \mathrm{~min}$ and red blood cells were removed by $1 \mathrm{X}$ BD lysis buffer (BD Biosciences, Franklin Lakes, NJ, USA) on ice for $1 \mathrm{~min}$, followed by centrifugation at $300 \mathrm{x} \mathrm{g}$ for 3 min. Primary cells were cultured for 3 weeks in Dulbecco's modified Eagle's medium (DMEM), supplemented with $10 \%$ fetal bovine serum (FBS) (Gibco ${ }^{\circledR}$; Thermo Fisher Scientific, Inc., Waltham, MA, USA). Floating cells were collected and re-cultured. Subsequent to subculturing for 15 passages, primary cells were identified by a tumor xenograft model; the tumor tissues were examined with hematoxylin and eosin staining and CA125 immunostaining.

Isolation of side population cells. The cells were trypsinized, resuspended at $1.0 \times 10^{6}$ cells $/ \mathrm{ml}$ in pre-warmed DMEM containing $2 \%$ flow cytometry staining buffer (CycleTEST $^{\text {тм }}$ PLUS DNA Reagent kit; BD Biosciences) and incubated at $37^{\circ} \mathrm{C}$ for $10 \mathrm{~min}$. The cells were labeled with $5 \mu \mathrm{g} / \mathrm{ml}$ Invitrogen $^{\text {TM }}$ Hoechst 33342 dye (Thermo Fisher Scientific, Inc.) at $37^{\circ} \mathrm{C}$ for $80 \mathrm{~min}$, alone or combined with $50 \mathrm{mM}$ verapamil (Sigma-Aldrich, St. Louis, MO, USA), an inhibitor of ABC transporters. The cells were counterstained with $1 \mu \mathrm{g} / \mathrm{ml}$ propidium iodide. In total, 100,000 cells were analyzed on a BD Influx cell sorter (BD Biosciences) and data were processed by BD FACSDiva version 6.1.1 software (BD Biosciences).

Tumorsphere formation assay. A total of 500 SP and non-SP (NSP) cells were plated onto a 24-well ultra-low attachment plate, and cultured in a DMEM/F12 serum-free medium (Gibco ${ }^{\circledR}$; Thermo Fisher Scientific, Inc.) supplemented with $4 \mu \mathrm{g} / \mathrm{ml}$ insulin (Sigma-Aldrich), $10 \%$ human leukocyte antigen B27 (Gibco ${ }^{\circledR}$; Thermo Fisher Scientific, Inc.), 20 ng/ml epidermal growth factor (EGF; Sigma-Aldrich), and $20 \mathrm{ng} / \mathrm{ml}$ basic fibroblast growth factor (bFGF; Sigma-Aldrich), for 10 days. Tumorspheres $>50 \mathrm{~mm}$ in diameter were counted under a phase-contrast microscope (IX50; Olympus Corporation, Tokyo, Japan).

Soft agar colony formation assay. A total of 200 SP and NSP cells were resuspended in a $0.8 \mathrm{ml}$ growth medium (DMEM with EGF, bFGF and B27) containing 0.3\% low-melting agarose (Sigma-Aldrich) and plated 3 times onto a 24-well plate pre-coated with a base layer of $0.8 \mathrm{ml}$ growth medium containing $0.6 \%$ low-melting agarose. The plates were incubated for 14-15 days until the size of colonies was large enough to count. Colonies $>75 \mu \mathrm{m}$ in diameter or colonies that possessed $>50$ cells were counted as positive colonies.

Xenograft tumor assay. In total, 45 female 5-week old non-obese diabetic-severe combined immune deficiency (NOD/SCID) mice weighing 16-20 g were purchased from Vital River Laboratories, Co., Ltd. (Beijing, China). The mice were housed in a sterilized room with $12 \mathrm{~h}$ light/dark cycle, at a temperature of $22^{\circ} \mathrm{C}$ with $40-60 \%$ humidity. Food and water were provided ad libitum. Animal experiment protocols were approved by the Ethical Committee of the First Affiliated Hospital of Jilin University (Changchun, China). Subcutaneously, $1.0 \times 10^{6}$ OC cells were injected into the dorsal flank of 5-week-old female NOD/SCID mice, and tumor formation and growth were observed after 6 weeks. SP and NSP cells were sorted by FACS and resuspended in serum-free DMEM. In $0.1 \mathrm{ml}$ DMEM, $3.0 \times 10^{3}$ or $3.0 \times 10^{4} \mathrm{NSP}$ and SP cells were subcutaneously injected into the dorsal flank of 5-week-old female NOD/SCID mice, or intraperitoneally injected into 5 -week-old female NOD/SCID mice $(n=5)$. Formation of tumor and ascites were examined subsequent to 3 weeks.

Drug resistance assay. SP, NSP and unsorted cells were seeded in 96-well plates at 3,000 cells/well. Subsequent to 24-h culture, cells were treated with $0.25,0.50,1.00,2.00,4.00,8.00$ and $16.00 \mu \mathrm{g} / \mathrm{ml}$ cisplatin (Sigma-Aldrich) for $72 \mathrm{~h}$. All treatments were run in triplicates. Cells without cisplatin treatment were used as negative controls. Following treatment, all cells were treated with $10 \mathrm{ml}$ cell counting kit-8 (CCK-8) reagent (Dojindo Molecular Technologies, Kumamoto, Japan) in $100 \mathrm{ml}$ complete high-glucose DMEM (Gibco ${ }^{\circledR}$; Thermo Fisher Scientific, Inc.) and cultured in normal culture conditions (DMEM with $10 \%$ FBS, $5 \% \mathrm{CO}_{2}$ at $37^{\circ} \mathrm{C}$ ) for $2.5 \mathrm{~h}$. In total, 3 wells without cells were used as blank controls. Absorbance at $490 \mathrm{~nm}$ was examined by a Model 550 microplate reader (Bio-Rad Laboratories, Inc., Hercules, CA, USA). Cell viability was determined by the following formula: Cell viability $(\%)=$ optical density (OD) values of drug-treated cells - OD values of blank controls] / (OD values of negative cells - OD values of blank control) x 100 . Cisplatin doses of $50 \%$ growth inhibition $\left(\mathrm{IC}_{50}\right)$ in SP, NSP and unsorted cells were calculated using Prism software, version 4.0 (GraphPad Software, Inc., La Jolla, CA, USA).

To additionally verify SP cell drug resistance, unsorted cells were treated with the $\mathrm{IC}_{50}$ dose of cisplatin for $3 \mathrm{~h}$ and cultured in a drug-free complete medium for $72 \mathrm{~h}$. The SP cell ratio was examined by FACS. To investigate the association between drug resistance and ABC transporters, SP cells were treated with $\mathrm{IC}_{50}$ dose of cisplatin or cisplatin with verapamil for $3 \mathrm{~h}$, and were then cultured in a drug-free complete medium for $72 \mathrm{~h}$. Cell viability was examined using the CCK-8 kit.

Statistical analysis. Statistical significance of differences between two groups was analyzed using two-tailed unpaired Student's t-test. Statistical analysis was performed using GraphPad Prism 5 software (GraphPad Software, Inc., La Jolla, CA, USA). Data are presented as the mean \pm standard error of the mean. $\mathrm{P}<0.05$ was considered to indicate a statistically significantly difference. 

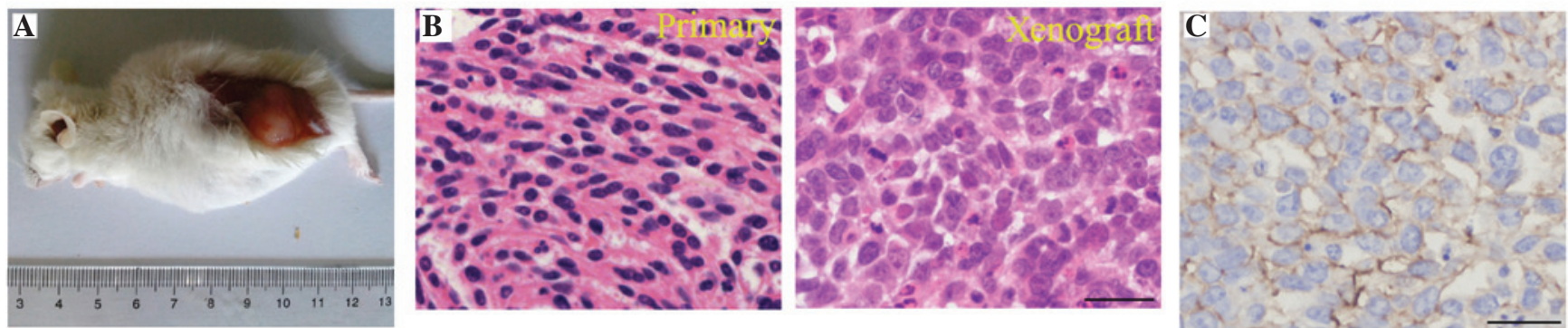

Figure 1. OC cell line generation. (A) Tumorigenesis of an established OC cell line: 1.0x10 ${ }^{6}$ OC cells were injected into the dorsal subcutaneous thigh of female non-obese diabetic/severe combined immune deficiency mice $(\mathrm{n}=3)$ and the tumor was observed 8 weeks later. (B) Histology of a primary OC tumor and xenografted OC tumor from an established OC cell line (hematoxylin and eosin staining; scale bar=100 mm). (C) Expression of ovarian serous cystadenocarcinoma marker CA125 in xenografted tumors by immunohistochemistry. Scale bar=100 mm. OC, ovarian cancer.
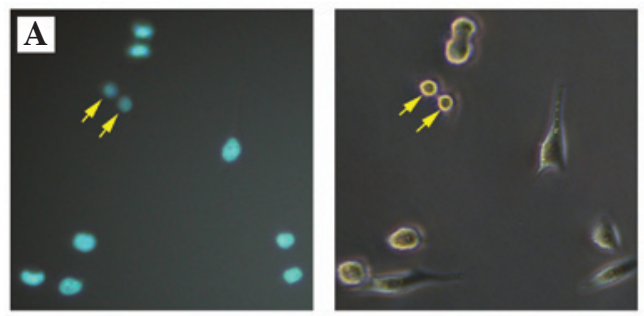

\section{B}

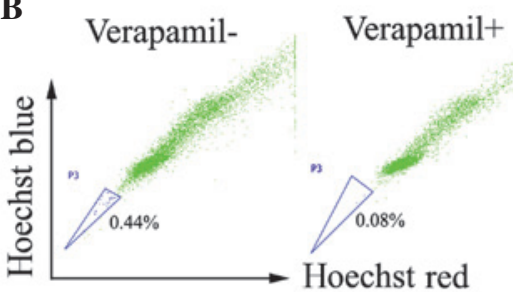

D

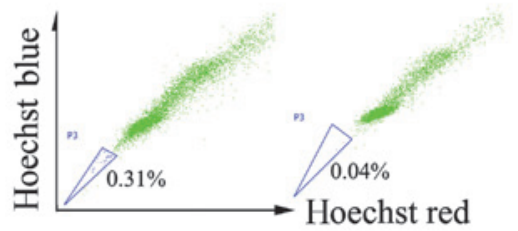

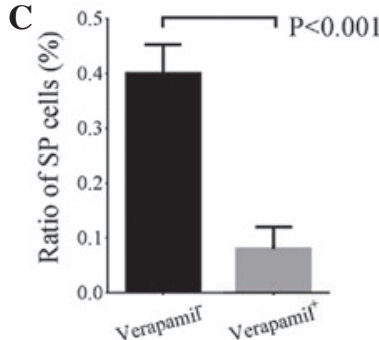

$\mathbf{E}$

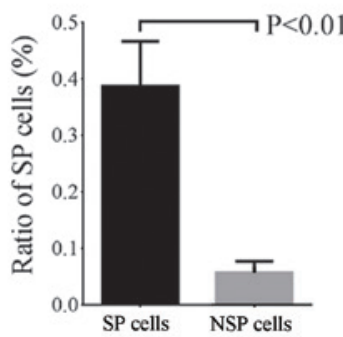

Figure 2. Identification of SP cells. (A) SP cell staining by Hoechst 33342 (left panel): Cells with low Hoechst staining (arrow) are SP cells. Contrast phase (right panel) was used to demonstrate the presence of SP cells. Population of SP cells in an established OC cell line with or without verapamil, which was (B) analyzed by FACS and $(n=1)(C)$ quantified $(P<0.001 ; n=3)$. Differentiation potential of SP and NSP cells: 1,000 SP and NSP cells were cultured for 3 weeks and the SP cell ratio was (D) analyzed by FACS $(n=1)$ and $(E)$ quantified $(\mathrm{P}<0.01 ; n=3)$. SP, side population; OC, ovarian cancer; NSP, non-SP.

\section{Results}

Establishment of human ovarian cancer cell line from ascites. Primary OC cells were purified from ascites of an ovarian serous cystadenocarcinoma patient (stage IIIc; grade 3) and cultured for $>50$ passages over 2 years. Subcutaneously, $1.0 \times 10^{6}$ OC cells were injected into the dorsal thigh of female NOD/SCID mice and tumor formation was examined subsequent to 8 weeks (Fig. 1A). No histological or cytological differences were observed between primary and xenografted tumors; the two tumors demonstrated poorly differentiated serous cystadenocarcinoma (Fig. 1B). Furthermore, the expression of ovarian serous cystadenocarcinoma marker CA125 was observed in the xenografted tumors (Fig. 1C) (24).

Isolation of SP cells from established OC cell line. SP cells possess low-fluorescence staining properties (21). FACS was used in the present study to isolate SP cells using Hoechst 33342 staining. Verapamil is an ABC transporter protein inhibitor that may effectively reduce the SP cell ratio (25). The present study observed weak Hoechst staining in certain cells, indicating that these are SP cells (Fig. 2A). The SP cell ratio in the OC cell line was $0.38 \%(n=5)$, while the SP cell ratio was significantly reduced in the presence of verapamil $(\mathrm{P}=0.001$; Fig. $2 \mathrm{~B}$ and $\mathrm{C})$.

Biological characteristics of SP cells: Differentiation potential of SP and NSP cells. To evaluate the differentiation potential of isolated SP cells, $1 \times 10^{3} \mathrm{SP}$ and NSP cells were cultured for 3 weeks and the SP cell ratios were compared between the two groups. The average SP ratio was $0.39 \%$ following SP cell culture for 3 weeks in vitro, which was a similar ratio to unsorted OC cells. The average SP ratio was $0.06 \%$ in NSP cells subsequent to 3 weeks of culture, which was significantly lower compared with SP and unsorted OC cells $(\mathrm{P}=0.004$; Fig. 2D and E). These results indicate that SP cells exhibited competent self-renewal and differentiation capacities in vitro, but NSP cells did not.

In vitro tumorsphere formation of SP and NSP cells. In total, 500 single SP and NSP cells were cultured in a serum-free medium supplemented with growth factor for 10 days, and 
A

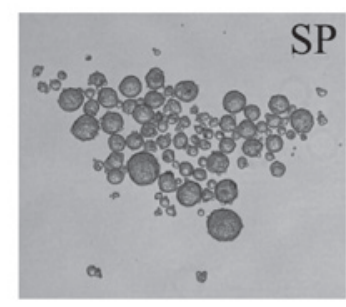

C
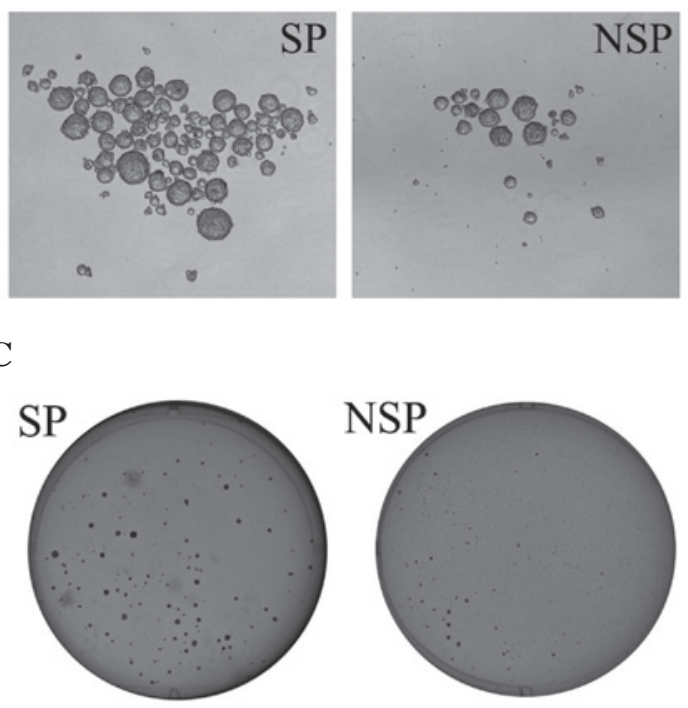

B
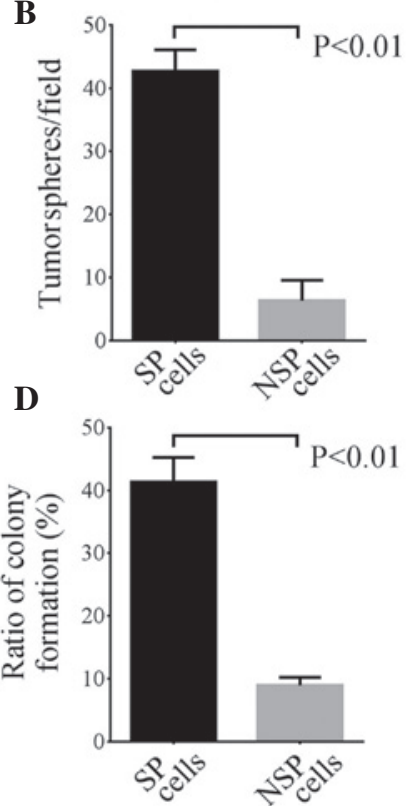

Figure 3. Tumorsphere and colony formation of SP and NSP cells. (A) Representative images of tumorsphere formation from SP (left panel) and NSP (right panel) cells. (B) Average number of tumorspheres/field in SP and NSP cells. Spheres $>50 \mu$ m in size were counted (P<0.01; $n=3)$. (C) Representative images of colony formation from SP (left panel) and NSP (right panel) cells. (D) Colony formation efficiency in SP and NSP cells. Clusters of $>50$ cells were counted $\left({ }^{*} \mathrm{P}<0.01 ; \mathrm{n}=3\right)$. SP, side population; NSP, non-SP.

tumorsphere formation was calculated. The present study demonstrated that the average number of tumorspheres formed in SP and NSP cells were 42.7 and 6.3, respectively $(\mathrm{P}=0.009$; Fig. 3A and B). These data indicate that SP cells possess improved self-renewal capacities compared with NSP cells.

SP and NSP cell colony formation. To further verify the present findings, 500 SP and NSP cells were seeded in soft agar medium and the cells were cultured for 14-15 days to observe the colony formation ratio. The present study observed that the colony formation ratio in SP cells (41.33\%) was significantly higher compared with NSP cells $(8.93 \%)(\mathrm{P}=0.008$; Fig. 3C and D). These data suggest that SP cells have greater colony formation capacities than NSP cells.

Tumorigenesis potential of SP and NSP cells. To evaluate the tumorigenesis potential of SP and NSP cells, 3.0x $10^{4}$ and $3.0 \times 10^{3} \mathrm{SP}$ and NSP cells were subcutaneously injected into the dorsal flank of the NOD/SCID mice. Xenografted tumors were observed in all 5 mice at $52\left(3.0 \times 10^{4}\right.$ cells $)$ and $63\left(3.0 \times 10^{3}\right.$ cells $)$ days subsequent to the injection of SP cells. None of the mice formed tumors 70 days following the injection of $3.0 \times 10^{3}$ NSP cells, and only 1 xenografted tumor was observed in 1 mouse at 54 days subsequent to injection of $3.0 \times 10^{4}$ NSP cells (Fig. 4A). Furthermore, the present study also evaluated the intraperitoneal tumorigenesis of SP and NSP cells. Following intraperitoneal injection of $3.0 \times 10^{4}$ cells into NOD/SCID mice, tumors were observed in the abdominal cavities of all 5 mice by 45 days post-injection, however, only 1 mouse demonstrated ascites and metastasis after 56 days (Fig. 4B and C). At 56 days post subcutaneous injection of $3.0 \times 10^{4}$ cells, the xenografted tumor size from SP cells was clearly larger than the size of the tumor from NSP cells (Fig. 4C). Similarly, the present study observed blood ascites and clear metastasis in the abdominal cavity of all 5 mice following the intraperitoneal injection of $3.0 \times 10^{3} \mathrm{SP}$ cells for 50 days, but this was not observed in any of the mice following the injection of the same amount of NSP cells for 56 days (Fig. 4B and D). These data indicate that the tumorigenesis potential of SP cells was significantly greater compared with NSP cells.

Histological and cytological characteristics. In addition, the present study investigated the histological and cytological differences between the primary and xenografted tumors. Similar to the primary tumors, xenografted tumors exhibited poorly differentiated serous cystadenocarcinoma histological and cytological features following subcutaneous and intraperitoneal injection (Fig. 5A). Furthermore, CA125 expression was observed in two types of xenografted tumors (Fig. 5B). These results verify that SP cells possess competent self-renewal and differentiation capacities in vivo.

Drug resistance of $S P$ cells. To investigate the drug resistance properties of SP cells, the present study treated SP, NSP and unsorted cells with $0.25,0.50,1.00,2.00,4.00,8.00$ and $16.00 \mathrm{~g} / \mathrm{ml}$ of cisplatin for $72 \mathrm{~h}$ and examined the cell viability using a CCK-8 kit. It was observed that the cell viability of SP cells was significantly higher compared with NSP and unsorted cells when treated with $1.0-4.0 \mathrm{~g} / \mathrm{ml}$ of cisplatin ( $\mathrm{P}=0.038$ vs. NSP cells; $\mathrm{P}=0.042$ vs. unsorted cells; Fig. 6A). However, there was no marked difference in cell viability following cisplatin treatment between NSP and unsorted cells (Fig. 6A). $\mathrm{IC}_{50}$ values for unsorted, SP and NSP cells were $1.75,2.38$ and 1.63 and $\mu \mathrm{g} / \mathrm{ml}$, respectively, and the $\mathrm{IC}_{50}$ value of SP cells was significantly higher than those of the NSP and unsorted cells $(\mathrm{P}=0.038$ vs. NSP cells; $\mathrm{P}=0.042$ vs. unsorted cells; Fig. 6B). These results indicate that SP cells exhibit 

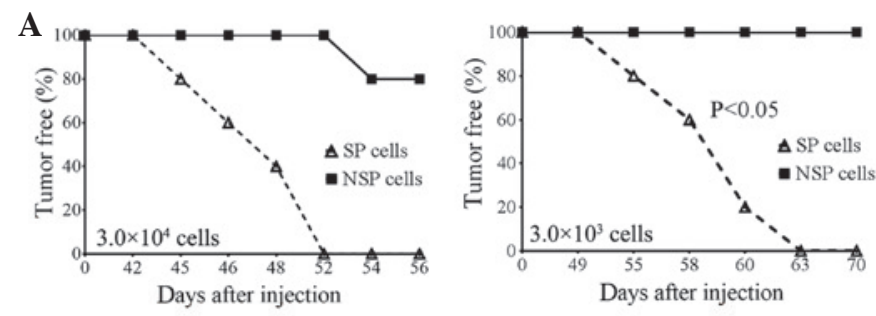

C

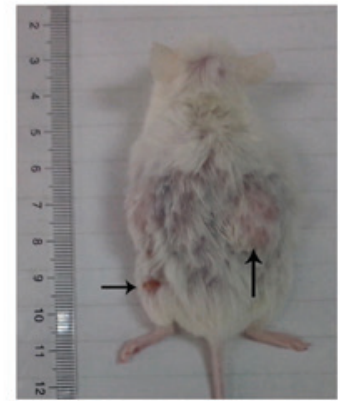

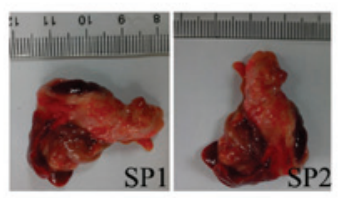

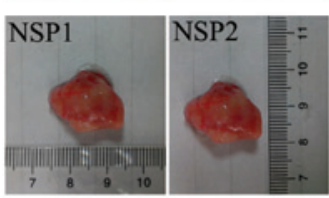

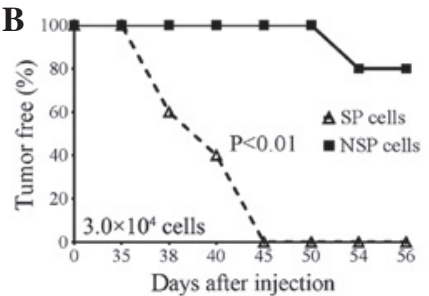

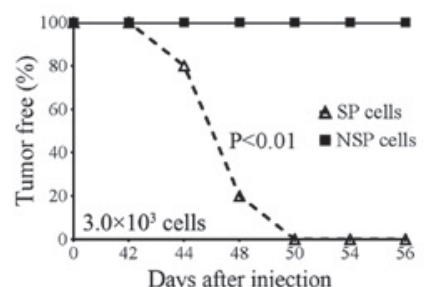

D
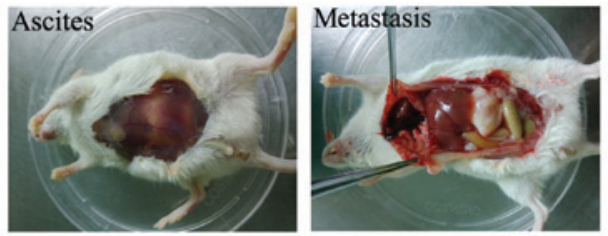

Figure 4. SP and NSP cell tumor formation. (A) Tumor-free curve in NOD/SCID mice following a (A) subcutaneous injection or (B) intraperitoneal injection of $3.0 \times 10^{4}$ or $3.0 \times 10^{3} \mathrm{SP}$ and NSP cells ( $\mathrm{n}=5$; P-value from log rank test). Xenografted tumor characteristics from SP and NSP cells. (C) 3.0x10 $0^{4} \mathrm{SP}$ and NSP cells were subcutaneously injected into NOD/SCID mice and xenografted tumors were observed in SP and NSP groups following 56 days (left panel). The tumor size from SP cells (top right panels) was significantly larger compared with that in the NSP cells (bottom right panels). (D) $3.0 \times 10^{3}$ SP and NSP cells were intraperitoneally injected into NOD/SCID mice. Blood ascites (left panel) and clear metastasis (right panel) in the abdominal cavity were observed in the SP group following 42 days. SP, side population; NSP, non-SP; NOD/SCID, non-obese diabetic/severe combined immune deficiency.

$\mathbf{A}$

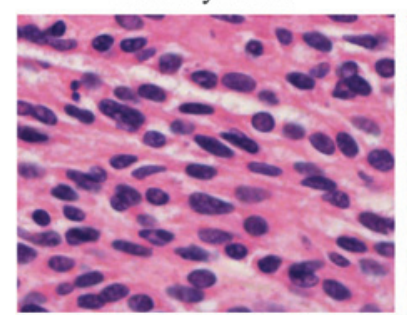

B

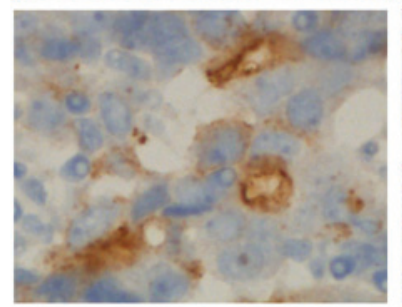

Subcutaneous xenografted tumor

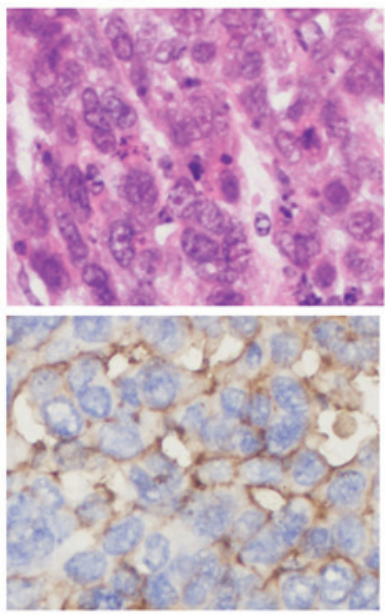

Intraperitoneal xenografted tumor

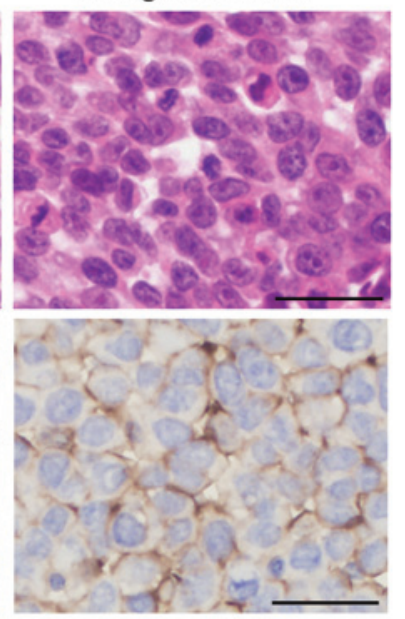

Figure 5. Histology and cytology of the different tumors. (A) Histology of primary tumor, subcutaneous xenografted tumor and intraperitoneal xenografted tumor (hematoxylin and eosin staining; scale bar=100 $\mu \mathrm{m}$ ). (B) Expression of ovarian serous cystadenocarcinoma marker CA125 in primary tumors, subcutaneous xenografted tumors and intraperitoneal xenografted tumors. Scale bar=100 $\mu \mathrm{m}$.

greater drug resistance capacities compared with NSP and unsorted cells. Furthermore, the SP cell ratio to unsorted cells was significantly elevated following cisplatin treatment, from 0.38 to $10.18 \%(\mathrm{P}=0.007$; Fig. $6 \mathrm{C})$. These data support the theory that SP cells are more resistant to cisplatin treatment compared with NSP and unsorted cells.

To clarify the association between drug resistance of SP cells and ABC transporters, the SP cells were treated with a $\mathrm{IC}_{50}$ dose of cisplatin or cisplatin + verapamil. The results demonstrated that cell viability was $71.41 \%$ following cisplatin treatment, while it was reduced to $6.00 \%$ following treatment with cisplatin + verapamil $(\mathrm{P}=0.006$; Fig. 6D). These data indicate that verapamil increases the sensitivity of SP cells to cisplatin treatment, suggesting that the drug resistance of SP cells to cisplatin depends on the drug efflux function of $\mathrm{ABC}$ transporters.

\section{Discussion}

Cancer cell lines are widely used in research to study the biology of cancer and examine cancer treatments. These cell lines can be cultured for long periods of time and share the tumor-associated biological characteristics of the original tumor (26). The present study successfully established an OC 

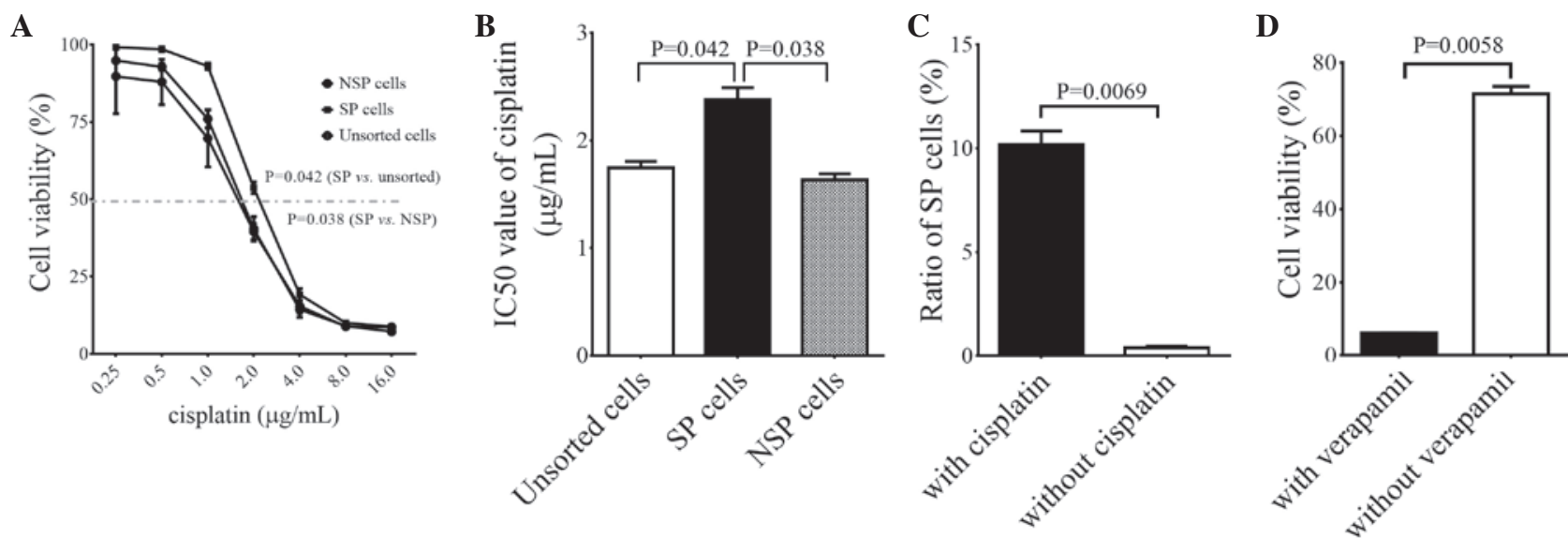

Figure 6. Drug resistance of SP, NSP and unsorted cells to cisplatin. (A) Titration of optimal cisplatin doses for SP, NSP and unsorted cells. (B) Cisplatin doses of $50 \%$ growth inhibition values for SP, NSP and unsorted cells, which were calculated by Prism version 4.0 software ( $\mathrm{P}<0.05$ vs. unsorted and NSP cells; $\mathrm{n}=3)$. (C) Cisplatin treatment increased the SP cell ratio in unsorted cells $(\mathrm{P}<0.01 ; \mathrm{n}=3)$. (D) SP cell drug resistance to cisplatin was abrogated by verapamil $(\mathrm{P}<0.01 ; \mathrm{n}=3)$. SP, side population; NSP, non-SP.

cell line from primary cells in ascites of an OC patient. This cell line had been passaged for 50 generations over 2 years and exhibited immortalized characteristics. Injection of this cell line into NOD/SCID mice formed xenografted tumors that revealed histological and cytological features similar to primary tumors. Therefore, this cell line would be a valuable tool for future functional studies on OC cancer.

Bonnet and Dick (27) first identified leukemia stem cells in 1997, which are tumor stem cells that have been isolated from various solid tumors, including breast, cerebral, colon, prostate, cervix and ovarian tumors (28-33). Numerous studies have demonstrated that certain molecular markers, including cluster of differentiation (CD)133, CD44 and CD117, may be used to isolate tumor stem cells $(24,34,35)$. However, certain cancer stem cells may lack these specific cell surface markers, or one type of stem-cell marker may only be specific to a particular tumor (36). SP cells within tumors are a small proportion of cancer cells with stem-like properties, which can be isolated by FACS due to their increased ability to export certain compounds, including Hoechst 33342 and chemotherapeutic agents. SP sorting is a type of functional sorting that has general applicability, compared with sorting stem cells by cell surface markers. Previous studies have demonstrated that SP cells partly overlap with corresponding stem cells, but SP cells in certain tumors, even the same type of tumor from various individuals, do not have stem cell properties (37-40). Therefore, the present study sought to investigate important characteristics, including self-renewal, differentiation ability and high tumorigenicity of SP cells from an established OC cell line.

The present study verified the average population of SP cells in our established cell line, which was $0.38 \%$, and the present results are similar to a previous study (0.01-5.00\%) (23). Stem cells have strong self-renewal capacities and form floating spheroids in a serum-free medium supplemented with growth factor, while differentiated tumor cells become apoptotic $(6,24)$. The present study additionally demonstrated that isolated SP cells exhibited significantly increased capacities in cell differentiation, colony formation and in vivo tumorigenesis compared with NSP cells. Furthermore, xenografted tumors from subcutaneous and intraperitoneal injections of SP cells exhibited histological and cytological features similar to primary tumors. These data indicate that isolated SP cells possess a number of important similar characteristics to OC stem cells, such as self-renewal, differentiation and high tumorigenicity. In addition, the present study identified that $1.0 \times 10^{4} \mathrm{NSP}$ cells was able to form tumors in a small proportion of mice, which contradicts previous studies $(39,41)$. It is possible that NSP cells may become contaminated with SP cells that induce tumor formation during the long culture period of $\sim 8$ weeks.

It is well established that OC stem-like SP cells are tumorigenic and chemoresistant $(41,42)$. The present study observed that isolated SP cells were more resistant to the first-line OC chemotherapy drug cisplatin. In addition, cisplatin treatment significantly increased the SP cell ratio. This observation is consistent with a recent study, in which SP cell ratio in ascites of patients with OC following chemotherapy was significantly higher compared with ascites of those that did not undergo chemotherapy (41). In OC clinical treatments, the majority of patients would gradually develop drug resistance following chemotherapy, which may be caused by SP cell accumulation. Furthermore, it has been demonstrated that $\mathrm{ABC}$ transporters are important in cisplatin-induced drug resistance in OC $(43,44)$. The present study identified an ABC transporter inhibitor (verapamil) that potently abrogated SP cell resistance to cisplatin, which is consistent with previous observations in OC cell lines (12). These data indicate that SP cell drug resistance to cisplatin depends on the efflux function of $\mathrm{ABC}$ transporters, suggesting a promising therapy for drug-resistant OC. In addition, previous studies demonstrated that increased chemoresistance of SP cells is associated with diverse mechanisms, including alterations in signaling pathways and enzymes, reduced apoptosis and increased DNA repair $(19,45,46)$. However, additional study is required to verify whether these mechanisms exist in SP cells from OC.

In summary, the present study successfully isolated and established an OC cell line. Isolated SP cells from the established OC cell line possessed similar biological 
characteristics as cancer stem cells, including self-renewal, differentiation, proliferation, tumorigenesis and drug resistance. This cell line and SP cells provide valuable models for studying $\mathrm{OC}$ tumorigenesis and drug resistance mechanisms that may aid in developing specific therapies for targeting OC $\mathrm{SP}$ or stem cells.

\section{Acknowledgements}

The present study was supported by the Jilin University Bethune plan B (grant no. B2012227) and Jilin Province Science and Technology Development Program (grant no. 20140520032JH).

\section{References}

1. Pecorelli S, Favalli G, Zigliani L and Odicino F: Cancer in women. Int J Gynaecol Obstet 82: 369-379, 2003.

2. Ozols RF: Update on the management of ovarian cancer. Cancer J 8 (Suppl 1): S22-S30, 2002.

3. Ozols RF: Treatment goals in ovarian cancer. Int J Gynecol Cancer 15 (Suppl 1): 3-11, 2005.

4. Cannistra SA: Cancer of the ovary. N Engl J Med 351: 2519-2529, 2004

5. Ozols RF, Bookman MA, Connolly DC, Daly MB, Godwin AK, Schilder RJ, Xu X and Hamilton TC: Focus on epithelial ovarian cancer. Cancer Cell 5: 19-24, 2004.

6. Reya T, Morrison SJ, Clarke MF and Weissman IL: Stem cells, cancer, and cancer stem cells. Nature 414: 105-111, 2001.

7. Zhou BB, Zhang H, Damelin M, Geles KG, Grindley JC and Dirks PB: Tumour-initiating cells: Challenges and opportunities for anticancer drug discovery. Nat Rev Drug Discov 8: 806-823, 2009.

8. Gottesman, MM: Mechanisms of cancer drug resistance. Annu Rev Med 53: 615-627, 2002.

9. Schatton, T, Murphy GF, Frank NY, Yamaura K, Waaga-Gasser AM, Gasser M, Zhan Q, Jordan S, Duncan LM, Weishaupt $\mathrm{C}$, et al: Identification of cells initiating human melanomas. Nature 451: 345-349, 2008

10. Yu, F, Yao H, Zhu P, Zhang X, Pan Q, Gong C, Huang Y, Hu $\mathrm{X}, \mathrm{Su} F$, Lieberman J and Song E: let-7 regulates self renewal and tumorigenicity of breast cancer cells. Cell 131: 1109-1123, 2007.

11. Zhou, S, Schuetz JD, Bunting KD, Colapietro AM, Sampath J, Morris JJ, Lagutina I, Grosveld GC, Osawa M, Nakauchi $\mathrm{H}$ and Sorrentino BP: The ABC transporter Bcrp1/ABCG2 is expressed in a wide variety of stem cells and is amolecular determinant of the side-population phenotype. Nature Med 7: 1028-1034, 2001.

12. Ito, K, Hirao A, Arai F, Matsuoka S, Takubo K, Hamaguchi I, Nomiyama K, Hosokawa K, Sakurada K and Nakagata N: Regulation of oxidative stress by ATM isrequired for self-renewal of haematopoietic stem cells. Nature 31: 997-1002, 2004.

13. Bao, S, Wu Q, McLendon RE, Hao Y, Shi Q, Hjelmeland AB, Dewhirst MW, Bigner DD and Rich JN: Glioma stem cells promote radioresistance by preferential activation of the DNA damage response. Nature 444: 756-760, 2006.

14. Diehn, M, Cho RW, Lobo NA, Kalisky T, Dorie MJ, Kulp AN, Qian D, Lam JS, Ailles LE, Wong M, et al: Association of reactive oxygen species levels and radioresistance in cancer stem cells. Nature 458: 780-783, 2009.

15. Goodell MA, Brose K, Paradis G, Conner AS and Mulligan RC: Isolation and functional properties of murine hematopoietic stem cells that are replicating in vivo. J Exp Med 183: 1797-1806, 1996.

16. Meirelles K, Benedict LA, Dombkowski D, Pepin D, Preffer FI, Teixeira J, Tanwar PS, Young RH, MacLaughlin DT, Donahoe PK and Wei X: Human ovarian cancer stem/progenitor cells are stimulated by doxorubicin but inhibited by Mullerian inhibiting substance. Proc Natl Acad Sci USA 109: 2358-2363, 2012.

17. Christgen M, Geffers R, Ballmaier M, Christgen H, Poczkaj J, Krech T, Kreipe H and Lehmann U: Down-regulation of the fetal stem cell factor SOX17 by H33342: A mechanism responsible for differential gene expression in breast cancer side population cells. J Biol Chem 285: 6412-6418, 2010.
18. Oates JE, Grey BR, Addla SK, Samuel JD, Hart CA, Ramani VA, Brown MD and Clarke NW: Hoechst 33342 side population identification is a conserved and unified mechanism in urological cancers. Stem Cells Dev 18: 1515-1522, 2009

19. Luo Y, Ellis LZ, Dallaglio K, Takeda M, Robinson WA, Robinson SE, Liu W, Lewis KD, McCarter MD, Gonzalez R, et al: Side population cells from human melanoma tumors reveal diverse mechanisms for chemoresistance. J Invest Dermatol 132: 2440-2450, 2012.

20. Mas A, Cervelló I, Gil-Sanchis C, Faus A, Ferro J, Pellicer A and Simón C: Identification and characterization of the human leiomyoma side population as putative tumor-initiating cells. Fertil Steril 98: 741-751, e6, 2012.

21. Gottesman MM, Fojo T and Bates SE: Multidrug resistance in cancer: Role of ATP-dependent transporters. Nat Rev Cancer 2: 48-58, 2002.

22. Dou J, Jiang C, Wang J, Zhang X, Zhao F, Hu W, He X, Li X, Zou D and Gu N: Using ABCG2-molecule-expressing side population cells to identify cancer stem-like cells in a human ovarian cell line. Cell Biol Int 35: 227-234, 2011.

23. Szotek PP, Pieretti-Vanmarcke R, Masiakos PT, Dinulescu DM, Connolly D, Foster R, Dombkowski D, Preffer F, Maclaughlin DT and Donahoe PK: Ovarian cancer side population defines cells with stem cell-like characteristics and Mullerian Inhibiting Substance responsiveness. Proc Natl Acad Sci USA 103: 11154-11159, 2006.

24. Zhang S, Balch C, Chan MW, Lai HC, Matei D, Schilder JM, Yan PS, Huang TH and Nephew KP: Identification and characterization of ovarian cancer-initiating cells from primary human tumors. Cancer Res 68: 4311-4320, 2008.

25. Jakubikova J, Adamia S, Kost-Alimova M, Klippel S, Cervi D, Daley JF, Cholujova D, Kong SY, Leiba M, Blotta S, et al: Lenalidomide targets clonogenic side population in multiple myeloma: Pathophysiologic and clinical implications. Blood 117: 4409-4419, 2011.

26. Douglas EJ, Fiegler H, Rowan A, Halford S, Bicknell DC, Bodmer W, Tomlinson IP and Carter NP: Array comparative genomic hybridization analysis of colorectal cancer cell lines and primary carcinomas. Cancer Res 64: 4817-4825, 2004.

27. Bonnet D and Dick JE: Human acute myeloid leukemia is organized as a hierarchy that originates from a primitive hematopoietic cell. Nat Med 3: 730-737, 1997.

28. Al-Hajj M, Wicha MS, Benito-Hernandez A, Morrison SJ and Clarke MF: Prospective identification of tumorigenic breast cancer cells. Proc Natl Acad Sci USA 100: 3983-3988, 2003.

29. Collins AT, Berry PA, Hyde C, Stower MJ and Maitland NJ: Prospective identification of tumorigenic prostate cancer stem cells. Cancer Res 65: 10946-10951, 2005.

30. O'Brien CA, Pollett A, Gallinger S and Dick JE: A human colon cancer cell capable of initiating tumour growth in immunodeficient mice. Nature 445: 106-110, 2007.

31. Singh SK, Hawkins C, Clarke ID, Squire JA, Bayani J, Hide T, Henkelman RM, Cusimano MD and Dirks PB: Identification of human brain tumour initiating cells. Nature 432: 396-401, 2004.

32. Zhang SL, Wang YS, Zhou T, Yu XW, Wei ZT and Li YL: Isolation and characterization of cancer stem cells from cervical cancer HeLa cells. Cytotechnology 64: 477-484, 2012.

33. Bapat SA, Mali AM, Koppikar CB and Kurrey NK: Stem and progenitor-like cells contribute to the aggressive behavior of human epithelial ovarian cancer. Cancer Res 65: 3025-3029, 2005.

34. Baba T, Convery PA, Matsumura N, Whitaker RS, Kondoh E, Perry T, Huang Z, Bentley RC, Mori S, Fujii S, et al: Epigenetic regulation of $\mathrm{CD} 133$ and tumorigenicity of $\mathrm{CD} 133^{+}$ovarian cancer cells. Oncogene 28: 209-218, 2009.

35. Clarke MF, Dick JE, Dirks PB, Eaves CJ, Jamieson $\mathrm{CH}$, Jones DL, Visvader J, Weissman IL and Wahl GM: Cancer stem cells - perspectives on current status and future directions: AACR Workshop on cancer stem cells. Cancer Res 66: 9339-9344, 2006.

36. Burkert J, Otto WR and Wright NA: Side populations of gastrointestinal cancers are not enriched in stem cells. J Pathol 214: 564-573, 2008.

37. Kai K, D'Costa S, Yoon BI, Brody AR, Sills RC and Kim Y: Characterization of side population cells in human malignant mesothelioma cell lines. Lung Cancer 70: 146-151, 2010.

38. Mitsutake N, Iwao A, Nagai K, Namba H, Ohtsuru A, Saenko V and Yamashita S: Characterization of side population in thyroid cancer cell lines: Cancer stem-like cells are enriched partly but not exclusively. Endocrinology 148: 1797-1803, 2007. 
39. Lichtenauer UD, Shapiro I, Geiger K, Quinkler M, Fassnacht M, Nitschke R, Rückauer KD and Beuschlein F: Side population does not define stem cell-like cancer cells in the adrenocortical carcinoma cell line NCI h295R. Endocrinology 149: 1314-1322, 2008.

40. Wu C, Wei Q, Utomo V, Nadesan P, Whetstone H, Kandel R, Wunder JS and Alman BA: Side population cells isolated from mesenchymal neoplasms have tumor initiating potential. Cancer Res 67: 8216-8222, 2007.

41. Rizzo S, Hersey JM, Mellor P, Dai W, Santos-Silva A, Liber D, Luk L, Titley I, Carden CP, Box G, et al: Ovarian cancer stem cell-like side populations are enriched following chemotherapy and overexpress EZH2. Mol Cancer Ther 10: 325-335, 2011.

42. Hu L, McArthur C and Jaffe RB: Ovarian cancer stem-like side-population cells are tumourigenic and chemoresistant. $\mathrm{Br}$ J Cancer 102: 1276-1283, 2010.
43. Moreno-Smith M, Halder JB, Meltzer PS, Gonda TA, Mangala LS, Rupaimoole R, Lu C, Nagaraja AS, Gharpure KM, Kang Y, et al: ATP11B mediates platinum resistance in ovarian cancer. J Clin Invest 123: 2119-2130, 2013.

44. Januchowski R, Zawierucha P, Andrzejewska M, Ruciński M and Zabel M: Microarray-based detection and expression analysis of $\mathrm{ABC}$ and SLC transporters in drug-resistant ovarian cancer cell lines. Biomed Pharmacother 67: 240-245, 2013.

45. Chen Y, Li D, Wang D, Liu X, Yin N, Song Y, Lu SH, Ju Z and Zhan Q: Quiescence and attenuated DNA damage response promote survival of esophageal cancer stem cells. J Cell Biochem 113: 3643-3652, 2012.

46. Li XX, Dong Y, Wang W, Wang HL, Chen YY, Shi GY, Yi J and Wang J: Emodin as an effective agent in targeting cancer stem-like side population cells of gallbladder carcinoma. Stem Cells Dev 22: 554-566, 2013. 